\title{
The Interpretative Phenomenological Analysis (IPA): A Guide to a Good Qualitative Research Approach
}

\author{
Abayomi Alase \\ School of Education, Northeastern University, Boston, Massachusetts, USA \\ E-mail: samuel-alase.a@husky.neu.edu; aalase@yahoo.com
}

Received: $27-02-2017$

doi:10.7575/aiac.ijels.v.5n.2p.9
Accepted: $30-03-2017$

URL: http://dx.doi.org/10.7575/aiac.ijels.v.5n.2p.9

Published: 30-04-2017

\begin{abstract}
As a research methodology, qualitative research method infuses an added advantage to the exploratory capability that researchers need to explore and investigate their research studies. Qualitative methodology allows researchers to advance and apply their interpersonal and subjectivity skills to their research exploratory processes. However, in a study with an interpretative phenomenological analysis (IPA) approach, the advantageous elements of the study quadruple because of the bonding relationship that the approach allows for the researchers to develop with their research participants. Furthermore, as a qualitative research approach, IPA gives researchers the best opportunity to understand the innermost deliberation of the 'lived experiences' of research participants. As an approach that is 'participantoriented', interpretative phenomenological analysis approach allows the interviewees (research participants) to express themselves and their 'lived experience' stories the way they see fit without any distortion and/or prosecution. Therefore, utilizing the IPA approach in a qualitative research study reiterates the fact that its main objective and essence are to explore the 'lived experiences' of the research participants and allow them to narrate the research findings through their 'lived experiences'. As such, this paper discusses the historical background of phenomenology as both a theory and a qualitative research approach, an approach that has transitioned into an interpretative analytical tradition. Furthermore, as a resource tool to novice qualitative researchers, this paper provides a step-by-step comprehensive guide to help prepare and equip researchers with ways to utilize and apply the IPA approach in their qualitative research studies. More importantly, this paper also provides an advanced in-depth analysis and usability application for the IPA approach in a qualitatively conducted research study. As such, this paper completely contrasted itself from many books and articles that are written with the premise of providing useful and in-depth information on the subject-matter (phenomenology, as a qualitative approach).
\end{abstract}

Keywords: Interpretative phenomenology analysis, IPA, qualitative research method approach

\section{Introduction}

Researchers who conduct research projects of different kinds may find it frustrating to decide on the qualitative research approach to use for their research projects. The truth of the matter is that it is not how many research approaches are out there in qualitative research methodology, but which one is flexible enough and 'participant-oriented' enough to get to the real 'lived experiences' of the research participants. As a guide for many new and novice researchers who are interested in conducting research projects in the following disciplines; education, sociology, psychology, political science, anthropology, economics, etc., the author felt it is important to update the research methodological approach he used in conducting his thesis research study to help inform and guide new researchers to a more comprehensive qualitative methodological tradition, The Interpretative Phenomenological Analysis (IPA) approach. The fact of the matter is that the thought of deciding on what research tradition or approach to use in a qualitative research study can be daunting and tedious. However, the good news is that qualitative researchers can take comfort in the fact that they have, at least, taken the first important step, the decision to conduct a qualitative research study. As in any life endeavor that has adversarial (contrarian) dimension, the issue that consumes many researchers of qualitative and quantitative research methodologies is what method can produce long lasting, credible, and transferable research findings. As such both methodologies (qualitative and quantitative) are somewhat in a 'state of competition' to see what methodology can produce the grandest research products.

With all that said, it is not the objective of this paper to cast blame or fault on either side; or even promote one side over the other. The primary objective and essence of this paper are to update and expand on the process that the author undertook in his thesis methodological journey; the author wants to show how advantageous the benefits are for utilizing the Interpretative Phenomenological Analysis (IPA). IPA approach can afford new and novice researchers the opportunity to explore, in more detail, the 'lived experiences' of the research participants. Smith, Flowers, and Larkin (2009), three of the most acknowledged modern-day minds (theorists) in the IPA approach, stated that "IPA is a qualitative research approach committed to the examination of how people make sense of their major life experiences" (p. 1). Additionally, they asserted that "IPA shares the views that human beings are sense-making creatures, and therefore the accounts which participants provide will reflect their attempts to make sense of their experience" (p. 4). As 
such, IPA is seen by many researchers and admirers of the approach as the most 'participant-oriented' qualitative research approach; a research approach that shows respect and sensitivity to the 'lived experiences' of the research participants.

\section{Key phenomenology theorists}

As a qualitative research approach, phenomenology was first conceptualized and theorized by Husserl (1931) as a way to understand the context of the 'lived experiences' of people (research participants) and the meaning of their experiences. However, many authors (theorists) have expanded on the theory to make it more aligned with the qualitative research methodology of today (Moustakas, 1994; van Manen, 1990). The theory of phenomenology has enlisted many brilliant minds and theorists in the expansion of its application and viability to its day-to-day usability by researchers of different educational discipline.

The following are examples of some of the brilliant theorists and minds who have written about the usability of the theory of phenomenology. Perhaps one of the best known theorist and author is van Manen. van Manen in 1990 wrote extensively about hermeneutical phenomenology. Hermeneutical phenomenology, according to van Manen (1990, p. 4) is the 'lived experiences' of research participants (phenomenology) and the interpretation (text) of the life they have lived and experienced (hermeneutics). Another well-known theorist and author is Moustakas. Moustakas in 1994 wrote about the psychological (also known as transcendental) phenomenology; in which he was less concerned about the interpretation of the researcher's personal experience and more focused on describing the 'lived experiences' of the participants in the research. Moustakas (1994) advocated what we now know as the "bracketing" of researcher's personal experience from that of the research participants' 'lived experiences'.

As a qualitative tradition, phenomenology is a well-known and well-used tradition, thus there are many less-known authors who have written or discussed some important aspects of the tradition in their research studies and/or in their writings. Giorgi (1994) is one of these authors. Giorgi (1994), a psychologist, discussed why it is important that phenomenological researchers understand the holistic (wholesome) usefulness of a phenomenological research study, so that they can make a strong and informed determination of the 'meaning unit'. This 'meaning unit' help transform and transfer the 'lived experiences' of the research participants into a sensitive psychological expressions, so that these experiences ('essences') can be written in a more reflective and descriptive manner (cited in Creswell, 2013).

Another phenomenology theorist and author is Riemen (1986). This author has written mostly in the medical field, especially in the area of caring, nursing. However, in order to develop a method of analysis for phenomenology, according to Creswell (2013, p. 194), Riemen formulated the 'meaning statements' from the significant statements in her "study of caring by patients and their nurses, she presents significant statements of caring and non-caring interactions for both males and females." Additionally, as a way for phenomenology to have uniformity in the "lived experiences' of research participants, Polkinghorne (1989), another phenomenologist, advised that phenomenological researchers should interview between 5 to 10 participants who have all experienced similar events (phenomenon). As such, the commonality of their experiences can be captured and interpreted.

Finally, the history of phenomenology as a qualitative approach will not be complete without mentioning the names of Smith, Flowers, and Larkin (2009). These theorists and authors have individually, and collectively, revolutionized the theory and concept of phenomenology in today's practice. As a credit to them, Smith, Flowers, and Larkin conceptualized and organized the new phenomenological research tradition called the interpretative phenomenological analysis (IPA). Again, to their credit, the functionality of the tradition (IPA) as a qualitative approach was superbly enhanced due to their collective efforts in redefining what the approach means and what it can do to help guide new and novice qualitative researchers in their quest to conduct qualitative research studies.

\section{Interpretative phenomenological analysis (IPA)}

According to Smith et al. (2009), as a qualitative tradition, IPA comes into its own "with the publication of Jonathan Smith's (1996) paper in Psychology and Health which argued for an approach to psychology which was able to capture the experiential and qualitative, and which could still dialogue with mainstream psychology" (p. 4). At this junction, they asserted that the aim of IPA was to "stake a claim for a qualitative approach central of psychology, rather than importing one from different discipline” (p. 4). As a qualitative approach, IPA started as a psychological-oriented approach. According to Smith et al. (2009),

IPA started in psychology and much of the early work was in health psychology. Since then it has been picked up particularly strongly in clinical and counseling psychology as well as in social and educational psychology. It is not surprising that the key constituency for IPA is what can broadly be described as applied psychology, or psychology in the real world. (p. 4-5)

Smith et al. (2009) also emphasized that they "prefer to use slightly different terms and to think of IPA's core interest group as people concerned with the human predicament" (p. 5). Underneath the approach, Smith and his colleagues felt that it was important that IPA be "seen as psychological - its core concerns are psychological, and psychology needs space for approaches concerned with the systematic examination of the experiential" (p. 5). Additionally, they stated that their "aim overall has been to show the developmental process of doing experiential qualitative psychology" (p. 5). As such, they reaffirmed the essence of what IPA is as an interpretative and navigating research approach. They stated that "The underlying philosophy of IPA is just as important as matters of procedure. Researchers who familiarize themselves with it will be able to produce more consistent, sophisticated and nuanced analyses" (p. 5). They argued that researchers who adhere to the underlying principles and philosophy of the tradition as they had articulated it "will 
also be able to draw on their [own] understanding of the underlying philosophy to help them to solve unanticipated problems, and as their confidence and experience grow, to develop their IPA work in ways which extend beyond the procedures described above" (pp. 5-6)

The key, however, to appreciating IPA as a qualitative research approach and what it can do is to appreciate its spirit and sensibility toward its desire to incorporate other knowledge and expand its own knowledge base. Smith et al. (2009) discussed the spirit and sensibility of IPA as being more than just a research tool, but as a tool that is looking to expand in its capacity. They stated that "IPA is not trying to operationalize a specific philosophical idea, but rather draws widely, selectively, from a range of ideas in philosophy" (p. 6). As such, the importance of IPA as a qualitative research approach is its ability to examine and interpret the 'lived experiences' of research participants. Smith et al. (2009) saw "phenomenological research as systematically and attentively reflecting on everything lived experience, and with Husserl (1931) we see that everyday experience can be either first-order activity or second-order mental and affective responses to that activity - remembering, regretting, desiring, and so forth" (p. 33). Furthermore, Smith et al. (2009) also stated that "in IPA, we are concerned with examining subjective experience, but that is always the subjective experience of "something"” (p. 33)

Smith et al. (2009) argued that the bottom line with IPA, as a tradition that is 'participant-oriented', is that the approach is more concerned with the "human lived experience, and posits that experience can be understood via an examination of the meanings which people impress upon it" (p. 34). Smith et al. (2009) said it best when they asserted that "Making sense of what is being said or written involves close interpretative engagement on the part of the listener or reader. However, one will not necessarily be aware of all one's preconceptions in advance of the reading, and so reflective practices, and a cyclical approach to bracketing are required" (p. 35). IPA researchers, in essence, represent a dual position. Smith et al. $(2009$, p. 35) posited that IPA "researcher is making sense of the participant, who is making sense of X." As such this double positional role that the IPA approach occupies makes the

Dual role of the researcher as both like and unlike the participant. In one sense, the researcher is like the participant, is a human being drawing on everyday human resources in order to make sense of the world. On the other hand, the researcher is not the participant, she/he only has access to the participant's experience through what the participant reports about it, and is also seeing this through the researcher's own, experientially lens. (p. 35-36)

As a qualitative research approach, IPA allows for multiple individuals (participants) who experience similar events to tell their stories without any distortions and/or prosecutions. Creswell $(2012$, p. 76$)$ stated that "a phenomenological study describes the common meaning for several individuals of their lived experiences of a concept or phenomenon." $\mathrm{He}$ also stated that "Phenomenologists focus on describing what all participants have in common as they experience a phenomenon" (p. 76). The most important aspect of IPA tradition is its ability to make sense of the 'lived experiences' of the research participants and truly allow the research study to explore the phenomenon that the research is investigating.

In today's research world, IPA approach is used in many qualitative research studies to investigate and interpret the 'lived experiences' of people who have experienced similar (common) phenomenon. According to Creswell (2013), "phenomenological study describes the common meaning for several individuals of their lived experiences of a concept or a phenomenon" (p. 76). He also asserted that "Phenomenology is not only a description, but it is also an interpretive process in which the researcher makes an interpretation of the meaning of the lived experiences." Furthermore, Smith et al. (2009) reiterated that

IPA is concerned with the detailed examination of human lived experience. And it aims to conduct this examination in a way which as far as possible enables that experience to be expressed in its own terms, rather than according to predefined category systems. This is what makes IPA phenomenological and connect it to the core ideas unifying the phenomenological philosophers.... (p. 32)

\section{Contrasting different approaches}

In a qualitative research methodology, there are varieties of data analytical approaches that researchers can utilize for their data analysis. Some of these analytical approaches are Narrative approach, Grounded Theory approach, Ethnographic approach, Case Study approach, the Interpretative Phenomenological Analysis (IPA) approach, etc. Arguments can be made for the justification of any one of these approaches (and in some cases, arguments are made). However, most of these data analysis approaches are aligned with the tradition that goes with their research designs. Therefore, for a case study research, it is appropriate for the researcher to utilize the case study data analysis approach, because it aligns well with the phenomenon that the study is investigating; the same holds true with the other data analysis approaches. Creswell (2013) said the following about the five data analysis approaches:

Across all five approaches, the researcher typically begins by creating and organizing files of information. Next, the process consists of a general reading and memoing of information to develop a sense of the data and to begin the process of making sense of them. Then, all approaches have a phase of description, with the exception of grounded theory, in which the inquirer seeks to begin building toward a theory of the action or process. (p. 200)

Creswell (2013) also stated that the participants' 'lived experiences' are what helps and guides many of these qualitative approaches make sense of their research analysis. However, what is most appreciated about the 
phenomenological approach is its ability to utilize the structured method of data analysis formula that Moustakas (1994) developed to help phenomenological researchers analyze their research data. The other qualitative approaches are as functional as they could be with their analysis; however, phenomenological approach goes a bit further. Creswell (2013, p. 193) explicitly truncated the added advantage of phenomenological approach; he stated that "The suggestions for narrative analysis present a general template for qualitative researchers. In contrast, in phenomenology, there have been specific, structured methods of analysis advanced." And this advancement by Moustakas is to give phenomenological researchers added advantage in their data analysis.

\section{Differences between IPA and general inductive approaches}

General inductive approach has been described as a qualitative research tradition that has the ability to analyze raw data to the objectives of the evaluators (researchers). Thomas (2006) asserted that "The primary purpose of the inductive approach is to allow research findings to emerge from the frequent, dominant, or significant themes inherent in raw data, without the restraints imposed by structured methodologies" (p. 238). Additionally, Thomas stated that "general inductive approach was used to analyze the qualitative data to identify themes in the text data that were related to the evaluation objectives" (p. 242). As a consequent, general inductive approach is consistent with Scriven (1991) "goal free" analysis that allows researchers to interpret their findings from the raw data collected as far as the data (findings) are relevant to the objective and goal of the evaluator (researcher).

As ideal and wonderful as the general inductive approach may sound, phenomenological research approach gives a lot more in-depth data collection and analysis processes than the general inductive approach. Even Thomas (2006) acknowledged that phenomenology "Seeks to uncover the meaning that lives within experience and to convey felt understanding in words" (p. 241). He also went on to say that phenomenology is a mechanic that interprets "A coherent story or narrative about the experience" of the research participants (p. 241). As qualitative traditions, this is where the two traditions differ, because unlike the phenomenological research tradition, general inductive approach tends to be more focused on finding themes and categories in the data collected that are relevant and conformity with the researcher's objectives. According to Thomas (2006), general inductive approach "provides an option for those evaluators who seek a simple, nontechnical means to carry out qualitative analyses" (p. 245). However, on the other hand, phenomenological approach will give in-depth descriptions and interpretations of the research participants' 'lived experiences' vis-à-vis how the phenomenon, which is being studied, has impacted the lives of the research participants.

\section{Research paradigms}

In order to have a truly conceptualized IPA research study, it is essential to have coherent paradigm/paradigms that will help put the concept together in a comprehensive manner. Interpretative phenomenological analysis is a tradition (or approach) that interprets and amplifies the 'lived experience' stories of research participants; however, for those stories to make-sense interpretively, the interpreter (researcher) of the stories must have a true and deeper understanding of the participants' 'lived experiences'. A way for a phenomenological researcher to have these understanding of the 'lived experiences' of the research participants, it is important for the researcher to put themselves in the shoes of the participants. Burrell and Morgan's (1979) and Guba's (1990) paradigms are some of the relevant paradigms useful in a phenomenological research studies.

The combination of Guba's (1990) critical theory paradigm and Burrell and Morgan's (1979) interpretive paradigm will be the two paradigms compatible and suitable enough to critically investigate and interpret the impact of the phenomenon on the 'lived experiences' of the research participants. Essentially, these two paradigms will identify and accentuate the problematic issues that are being investigated, and help to interpret the impact of the problems on the 'lived experiences' of the research participants. These paradigms may be operationally different, in terms of their applicability, if utilized separately and individually; however, with both of them working together in concert with each other, they can get to the ultimate goal of an IPA research study which is to explore, investigate and interpret the 'lived experiences' of the research participants. On one hand, Guba's (1990) critical theory paradigm can set the stage for the exploration of the phenomenon experienced by the research participants; and on the other hand, Burrell and Morgan's (1979) interpretive paradigm can explicitly and interpretively narrate how the phenomenon has impacted the 'lived experiences' of the research participants.

\section{The role of phenomenological researchers}

As a qualitative (phenomenology) researcher, it is the role and responsibility of the researcher to investigate and interpret the impact of the research subject-matter on the 'lived experiences' of the research participants. Additionally, Creswell (2012) argues that "The purpose of a proposal is to help an investigator think through all aspects of the study and anticipate problems" (p. 268). As for an IPA approach, the essence of the approach is to understand and amplify the "lived experiences" of the research participants that the research project is investigating. According to $\mathrm{Wu}$ and $\mathrm{Wu}$ (2011), qualitative researchers "focuses on context analysis, explores the deeply-rooted causes of phenomena, and highlights the explanations of what happened" (p. 1305). Additionally, Flick (2010) stated that qualitative researchers have the "specific understanding of the relation between issue and method" (p. 90). Consequently, as a qualitative instrument (tradition) that investigates and interprets phenomena issues, it is appropriate for qualitative researchers to elect and utilize the IPA research tradition, because of its uniqueness and suitability to investigate and interpret the 'lived experiences' of the research participants.

Therefore, as qualitative researchers, the role of an IPA researcher is to explore and maximize the potential opportunities and possibility that the tradition (approach) affords him/her. It is very important that the research 
participants have an avenue to share their 'lived experience' stories without fear of distortions and/or prosecutions. Moustakas (1994, p. 135) stated that it is important to understand the "underlying dynamics of the experience" of the participant. He advised that in order to capture the essence of a true research investigation, researchers must endeavor to bracket themselves away from the issue that they are investigating. He stated that we must "set aside our prejudgments, biases, and preconceived ideas about things" we are trying to understand (Moustakas, 1994, p. 85). However, that may be hard to do as a qualitative research, the bottom line is that the intent of an IPA research approach is to tell the true 'lived experience' stories of the participants, so that when readers reflect on them, they can equally say to themselves what Polkinghorne (1989) altered in his book, "I understand better [now] what it is like for someone to experience that" (p. 46).

Finally as a research tradition that is interpretative, interpersonal, and interactive in nature, qualitative research approach (IPA) is endowed with a lot of features that can help equip its studies (and researchers) with rich abundance of data insight and holistic flavor to the stories that are being explored. Consequently a qualitative approach like IPA is equipped with all the necessary tools and mechanisms needed to conduct a rich and 'thick descriptive' research study.

\section{Research questions}

In a qualitative research study, the research questions should encapsulate the essence of what the research study is trying to uncover (the ontological, epistemological and methodological stance of the research study). According to Trede and Higgs (2009), "Research questions embed the values, world view and direction of an inquiry. They also are influential in determining what type of knowledge is going to be generated" (p. 18). Additionally, Creswell (2003) recommended that qualitative researchers only "ask one or two central questions followed by no more than five to seven sub-questions. Several sub-questions follow each general central question, and the sub-questions narrow the focus of the study but leave open the questioning" (p. 106). In addition to posing the central and sub-central questions to participants, as a rule, it is important that qualitative researchers utilize the open-ended question formula. Creswell (2003) advised researchers to "Use open-ended questions without reference to the literature or theory unless otherwise indicated by a qualitative strategy of inquiry" (p. 107). The bottom line is that the wording of the research questions should be in a way probing and open-ended.

\section{Participants and sampling strategy}

As for the research population and sample size, Creswell (2012) suggested that "When selecting participants for a study, it is important to determine the size of the sample you will need" (p. 146). Likewise, in a phenomenological research tradition, the size of the participants can be between 2 and 25. The selection of these participants should reflect and represent the homogeneity that exists among the participants' sample pool. The essence of conducting an IPA research study with homogenous participants is to get a better gauge and a 'better understanding' of the overall perceptions among the participants' 'lived experiences'. Additionally, Creswell (2013) stated that "It is essential that all participants have [similar lived] experience of the phenomenon being studied" (p. 155).

As part of the process of selecting participants for a phenomenological research study, Creswell (2013) stated that it is "important [that phenomenological research study endeavor] to obtain participants' written permission" (p. 154). In addition to the fact that it is advisable for the IPA researcher to seek the written approval of the participant, Creswell (2012) also stated that in any qualitative research study, it is important that "you select people or site that can best help you understand the central phenomenon" (p. 206). Therefore, in a phenomenological research investigation there should be two objectives in mind: One is to either corroborate the 'lived experiences' as told by the research participants in an 'across the board' corroboration; or two, dispute the allegations altogether, if they're not found to be true or credible. However, in order for the research study to be able to do any of these, it is imperative that a phenomenological research study seek and obtain the approved 'informed consent' from the participants before any study can commence. According to Creswell (2013), in a phenomenological research study where all the participants have experienced similar phenomenon, it is "important to obtain participants' written permission to be studied" (p. 154).

As stated above, in a phenomenological research study, participant must be selected from amongst a homogeneous sample pool of participants to understand the true make-up of the research subject-matter. Smith et al. (2009) stated that "samples are selected purposively (rather than through probability methods) because they can offer a research project insight into a particular experience" (p. 48). Additionally, because of the homogeneity of the research participants and the size of the sample pool, it is anticipated that IPA research studies will be rich and descriptively deep in its analytical process. Smith et al. (2009) emphasized that "IPA studies are conducted on relatively small sample sizes, and the aim is to find a reasonably homogeneous sample, so that, within the sample, we can examine convergence and divergence in some detail" (p. 3).

As aforementioned, an IPA research study should select participants from a homogeneous sample pool. Therefore, in an IPA selection and invitation processes, there are multiple ways to select and invite participants to a research project. One way is to send invitation letters to prospective participants. In addition to that, if for any reason the number of participants is not reached, a snowball strategy can be applied to help attract more participants to the research. This snowball strategy will be based on soliciting the advice and help of the participants who have already agreed to participate in the research project to help 'put in good words' to attract other participants to join in the research project. More importantly, as a qualitative research approach, the essence of an IPA research project is to get 'rich' and 'thick descriptions' of the "lived experiences" of the research participants (Geertz, 1973). As such, Smith et al. (2009) advised that the primary concern of "IPA is with a detailed account of individual experience. The issue is quality, not quantity, 
and given the complexity of most human phenomena, IPA studies usually benefit from a concentrated focus on a small number of cases" (p. 51).

\section{Data storage and management}

Securing and managing the data collected in a qualitative research study cannot be over-emphasized. As the manager of the research data base, it is the responsibility of the researcher to provide adequate security for the safekeeping of the data that was collected. Alase (2016) suggested the following measures for securing and safeguarding the research data from outsiders. He stated that

As an added protection, an IPA research study should destroy through deletion of any video, audio and/or taped recorded information after it has been transcribed for the safety and protection of the participants. Additionally, IPA study should also provide a safe and sturdy storage system for the safekeeping and management of the research data. Rubin and Rubin (2012) advised that researchers should have a sturdy safety system that protects the data collected from the hands of any outsider, i.e., providing a protected password system for the filing and storing of research data. (p. 85)

\section{Interview scheduling}

At the commencement of a phenomenological research study, the chosen participants should be sent the informed consent forms and other necessary letters asking for their participation in the research study. Once their approvals are obtained, the interviews shall officially commence. One thing that the study should be cognizant of is the 'time factor'. According to Flick (2010), "One factor is frequently undervalued in the development of a research design. The available resources like time, personnel, technical support, competencies, experience, and so on are very important factors" (p. 131). Therefore, the researcher in a phenomenological research study should endeavor to conduct and conclude the participants' interviews within a very reasonable time period (this time period should account and allow for any additional follow-up interviews to be conducted, in case of any verifiable confirmations).

Additionally, as much as researchers want to believe that they can anticipate what to expect in an interview session with their research participants, the fact of the matter is that there are so many unpredictability elements that can come up at the interview sessions vis-à-vis their participants' actions or inactions with respect to their responses. Therefore, the advice is that IPA researchers should be prepared to expect the unknown when it comes to the actions and/or inactions of their research participants in an interview session. Furthermore, at the beginning of any research interview session, it is advisable that the researcher try to develop some kind of rapport with their research participants so that they, the research participants, can 'lighten-up' and feel relaxed about the process before the interview session commence. The first thing the researcher wants to do in an interview session is to follow the advice that Smith et al. (2009) suggested; they suggested that

The most important thing at the beginning of the interview is to establish a rapport with the participant. They need to be comfortable with you, to know what you want and to trust you. Unless you succeed in establishing this rapport, you are unlikely to obtain good data from your participant. (p. 64)

In addition to the above advice, Smith et al. (2009) also argued that "Good research interviewing requires us to accept, and indeed relish, the fact that the course and content of an interview cannot be laid down in advance" (p. 65). Therefore, the bottom line is that in an IPA interview process, the researchers have to learn how to put the participants at ease with regard to asking them about their 'lived experiences'.

\section{Data collection process}

It is important that the 'lived experiences' of the research participants be allowed to tell the narration of the research study. According to Creswell (2013), in a phenomenological research study, "the process of collecting information involves primary in-depth interviews with as many as 10 individuals. The important point is to describe the meaning of the phenomenon for a small number of individuals who have experienced it" (p. 161). Additionally, in order to obtain the full and unhindered data collection on the phenomenon that the study intends to investigate, an IPA study should, in addition to the traditional ways of data collection processes, utilize the search engines of the Internet system as a way to gather additional information. Creswell (2013) asserted that data gathered through the "Internet has the advantages of cost/time efficiency in terms of reduced cost for travel and data transcription. It also provides participants with time and space flexibility that allows them more time to consider and respond to requests for information" (p. 159). Furthermore, Creswell (2013) also stated that "online data collection helps create a nonthreatening and comfortable environment, and provide greater ease for participants discussing sensitive issues (Nicholas et al., 2010)" (p. 159).

The process of collecting and analyzing data for a qualitative research study can be tedious and cumbersome, hence the reason why thorough and detailed informational background needs to be provided to the Institutional Review Board (IRB) before the research can commence. Flick (2010) advised that "If you set up a research design, I would advise you to take into account what your goals of generalization are in your study" (p. 130). Creswell (2012) added that "Because qualitative data collection consists of lengthy periods of gathering information directly involving people and recording detailed personal views from individuals, you will need to provide a detailed description of your procedure to the institutional review board" (p. 210). Gathering in-depth oriented information for a research study can be very demanding. This process involves asking participants to divulge personal and private details about themselves. Creswell (2012) stated that "gathering data for qualitative project, a researcher seeks an in-depth description of a 
phenomenon. Participants may be asked to discuss private details of their life experiences over a period of time" (p. 230). Additionally, Wolcott (1983) asserted that it would be "impossible to embark upon research without some idea of what one is looking for and foolish not to make that quest explicit” (p. 57).

In a phenomenological approach, the only time that a researcher has to bracket or keep his/her preconception out of the process is during interviews of participants and collection of research data. Smith et al. (2009) argued that "The IPA approach to data collection is committed to a degree of open-mindedness, so you will have to try to suspend (or bracket off) your preconceptions when it comes to designing and conducting interviews or other data collection events" (p. 42). The reason for bracketing one's preconception during interviews, according to Smith at al. (2009), is to "enable participants to express their concerns and make their claims on their own terms" (p. 42).

In describing the process of data collection, Creswell (2012) noted that the process involves more than just simple data gathering, "It involves the steps of determining the participants to study, obtaining permission needed from several individuals and organizations, considering what types of information to collect from several sources available to the (qualitative) research" (p. 140-141). The process of selecting the right research participants for the study can sometimes be tedious and daunting, because researchers are trying to appropriately invite the right participants to their research studies. But as a qualitative research tradition, phenomenological approach (IPA) will give the study the best chance of collecting rich and accurate data. Smith et al. (2009) put it more concisely by saying that "As with many other approaches in qualitative psychology, the essence of IPA lies in its analytic focus. In IPA's case, the focus directs our analytic attention towards our participants' attempts to make sense of their [lived] experiences" (p. 79).

IPA is known for its ability to gather rich and 'thick descriptive' research data; Smith et al. (2009) eloquently stated that "A qualitative research interview is often described as 'a conversation with a purpose'. This purpose is informed, implicitly at least, by a research question" (p. 57). As a 'conversational' and interpretative data collection method, IPA interviews are meant to open up and develop a relationship with the participants so that their 'live experiences' can be explored and analyzed. Smith et al. (2009) asserted that "the aim of an [IPA] interview is largely to facilitate an interaction which permits participants to tell their own stories, in their own words" (p. 57). As a 'participant-oriented' research approach, IPA researchers are able to develop bonds with their participants; these bonds are developed through interpersonal and interactive relationships; thus the relationships allow for smooth information gathering and easier analysis. More importantly, Smith et al. (2009) stated that the "Interviewing [process] allows the researcher and participant to engage in a dialogue whereby initial questions are modified in the light of participants' responses, and the investigator is able to enquire after any other interesting areas which arise" (p. 57). As such, the following steps should constitute data collecting procedures for an IPA study:

- $\quad$ An IPA research study should conduct semi-structured and unstructured interviews with as many as twenty five (25) participants, but as few as two (2).

- The interview duration should be approximately sixty to ninety minutes in duration per interview session

- $\quad$ The study should keep the interview invitation to one interview per participant. However, only if there is a need for a follow-up interview shall the researcher contact the participants for additional interviews.

- The site (including the date, time and place) for the interviews should be left to the participants to decide. However, the researcher's natural first choice and preference should always be at the participants' place of comfort, for convenience purposes to the participants. But if need be, a safe and comfortable alternative place should be provided for the meetings by the researcher (i.e., at restaurants, coffee shops and/or any other convenient outlets).

- Finally, the research study should utilize different technological devices to collect necessary data (i.e., electronic voice recording devices and video recording devices, if need be). And naturally, the traditional 'note and pen' should be used for jotting down important observations as the interviews progress.

To adhere to the IRB human protection requirements, all of the devices, techniques and strategies should only be used with the full consent and approval of the participants. Additional useful tool that an IPA research study can utilize is the 'interview protocol' tool developed by Asmussen and Creswell (1995). This protocol, according to Creswell (2013, p. 168), allows a "person to take notes during the interview about the response of the interviewee. It also helps a researcher to organize thoughts on items such as headings, information about starting the interview, concluding ideas, information on ending the interview..."

\section{Data coding procedure and process}

In a qualitative research study one thing that many new and novice researchers get bogged down on when they are in the process of analyzing the interview transcripts for their research is the data coding process. Data coding can be strenuous and unnecessarily bothersome. As one of the most essential elements of qualitative research process, data coding procedures and processes can be confusing and frustrating; it is perhaps one major reason why this paper was actually conceived, because the author wanted to remove the mysticism that is associated with data coding processes and procedures; a process and procedure that is very mysterious to many new and novice researchers. The first thing that a researcher does when he/she is about to embark on a data coding process is for him/her to read through the interview responses to identify common themes; search for words or phrases that are repeated in the participants' responses; this can help the researcher narrow down (condense) the words or sentences in a transcript. The next step for the researcher is to re-read each transcript (and/or listen to any recording devices used during the interviews), again, for clarity. Perhaps after reading the transcript for the third time, the researcher can probably come up with some themes 
and categorizations in the pattern of responses by the research participants. It is without a doubt that this type of data analysis can be laborious; however, as a process it is very useful. As a matter of fact, Mertler (2006) forewarned that "researcher[s] may feel a bit overwhelmed with the task that lies ahead, as it can seem a monumental undertaking" (p.125). Additionally, Smith et al. (2009) also advised that qualitative research methodology is one of those methodologies that are "time-consuming, labour-intensive, and both imaginatively and emotionally demanding" (p. 42). In a qualitative data coding process, researchers are advised to begin their data coding by reading the interview transcripts several times; at least, they are encouraged to read the transcripts three times to get a feel of what the research participants were saying verbally, and also to get a better feel of the participants' 'state of mind' vis-à-vis how the subject-matter has affected their 'lived experiences'. In essence, this is the 'meaning unit'; meaning unit, according to Graneheim and Lundman (2004) are bunch of words or statements that relate to the same 'core essence' or ("central meaning") of the 'lived experiences' that the research participants are trying to convey through their responses.

According to Alase (2016), data coding requires three generic cycles. The first generic cycle is a process that gradually codes the sometime lengthy and convoluted responses by research participants into meaningful chunky statements (or sentences). This process is meant to help researchers break-down the responses into a format (i.e., block of sentences or statements) that they, the researchers, can condense and manage. This process can also help researchers be mentally aware of some key words or phrases that are repeated or expressed by the participants. These words or phrases can sometimes mean a lot to the veracity of what the participants are trying to convey to the researcher. In fact, in some cases, these phrases can mean the 'core essence' of the participants' 'lived experiences' has it relate to the research project subject-matter.

The second generic cycle is another condensation process that further help the researcher reduce the first generic chunky statements (or sentences) into fewer words to move closer to the 'core essence' of what the research participants were actually expressing. This second data condensation gives the researcher another opportunity to extrapolate in very few tangible words the true 'gist' (or 'core essence') of what the research subject-matter has meant to the 'lived experiences' of the participants. Alase (2016) stated that "even though the first [and second] coding process[es] will break down the participants' responses into manageable format, the condensed coding will still accurately represent the thoughts and "lived experiences" of the participants" (p. 88)

More importantly, the third and final generic cycle stage is what Alase (2016) described as the category phase (or stage). This stage allows researchers to narrow down to extremely few words the responses of the participants. In this final stage, the category stage, what the researcher is trying to do is to encapsulate (capture) the 'core essence' of the central meaning (meaning unit) of the research participants' 'lived experiences' in one or two words. Alase (2016) stated that "Utilizing the generic coding method allows the researcher to meticulously and methodologically break down the participants' responses without diminishing or misrepresenting the core meaning of their responses or "lived experiences" (p. 88-89)

Finally, researchers are also encouraged to use the same process to develop their research themes. By utilizing similar process, the researcher has positioned himself or herself to capture and represent the 'core essence' of the 'lived experiences' of the research participants without distorting or misrepresenting the 'core essence' of what the participants have experienced.

\section{Data analysis process}

To analyze qualitative data, IPA researchers are encouraged to observe the guidance set forth by Moustakas. Moustakas (1994) advanced series of methods that phenomenological researchers were advised to utilize in analyzing their studies. The idea was that IPA researchers will have a more cohesive analysis method that will reflect the phenomenological philosophy in their research study. As a tradition that encourages researchers to "bracket" themselves away from the 'lived experiences' of the research participants; Creswell (2013) advised researchers to "First describe [their own] personal experience with the phenomenon under study. The researcher [should] begin with a full description of his or her own experience of the phenomenon" (p. 193). In this way, the researcher should avoid interjecting his/her personal experiences into the 'lived experience' stories of the research participants. Additionally, Creswell (2013) advised that researchers should "Develop a list of significant statements" as a foundation to understanding the phenomenon (p. 193). These statements can come from interviews and other relevant research sources that speak to the experience that's being studied; Creswell (2013) suggested that researchers should "treat each statement as having equal worth, and works to develop a list of non-repetitive non-overlapping statements" (p. 193).

According to Creswell (2013), after the development of these statements, researchers should "Take the significant statements and then group them into larger units of information, called "meaning units" or themes" (p. 193). The next step, after grouping the significant statements to form a large unit of information, Creswell (2013, p. 193) suggested that researchers should "Write a description of "what" the participants in the study experienced with the phenomenon." According to Creswell (2013), this is known as the "textural description" of the participants' experiences, and the written descriptions of what happened to the research participants must include verbatim examples. At this stage of the phenomenological method of analysis, Creswell (2013, p. 194) suggested that researchers should write a "description of "how" the experience happened." In essence, writing the description of the "how" is what Creswell (2013, p.194) referred to as "structural description," so that the researcher is able to reflect "on the setting and context in which the phenomenon was experienced." Finally, Creswell (2013, p 194) advised researchers to "write a composite description of the phenomenon incorporating both the textural and structural descriptions." More importantly, Creswell (2013) 
argued that "This passage is the "essence" of the experience and represents the culminating aspect of a phenomenological study" (p. 194).

In a qualitative research analysis, the interview transcript should be transcribed verbatim into a hard copy and then analyzed by utilizing the color-coded (or any other practical methods) and categorization for analyzes (i.e., common themes). Miles, Huberman, and Saldana (2013) stated that "Credible and trustworthy analysis requires, and is driven by display that are focused enough to permit a viewing of a full data set in the same location and are arranged systematically to answer the research questions at hand" (p. 108). More importantly, in a phenomenological research study (IPA), Smith et al. (2009) argued that IPA research approach has the ability to explore, in a deep way, the 'lived experiences' of research participants and help to understand the phenomenological significance of this experience and how it impact the participant (as cited in Alase, 2016).

The last step of the structured phenomenological traditional method of analysis is the long paragraph; the researcher must write a mini statement that tells the audience (readers) "what" the research participants have experienced and "how" they experienced the phenomenon in a contextual format.

\section{Tools and mechanisms for creating credible and transferable findings in an IPA research study}

As a qualitative research tradition, the intention of a phenomenological analytical approach like IPA is to investigate and interpret the 'lived experience' of any research participant with the desired objective to understand the experience from the perspective of the participant, and try to amplify it. As such, an IPA research study should develop mechanisms (tools) that will allow for the research data and findings to be thoroughly authenticated so that the end results are not cued or defective. According to Alase (2016), IPA research studies must have the following mechanisms (trustworthiness, member-checking, triangulation, and auditing) as tools for navigating any phenomenological data gathering and analyzes; however, another tool is now added as a fifth mechanism. Quality and verification tool is another tool that is going to help authenticate and verify that all the above mechanisms (tools) are doing their jobs in the authentication and verification of the phenomenological research data and findings. The function of this tool is to look comprehensively at all the information gathered to make sure that every one of them has met, at least, the minimum standards required for attaining credible and transferable results for an IPA research study. As a qualitative and interpretative analyzing research approach, the veracity of its claim and authentication has to be beyond reproached. As such, creating a mechanism like the quality and verification tool (mechanism) is very essential, and also as an added safeguard to its credibility as a qualitative research approach.

15.1 Quality and verification of data as the fifth mechanism

Quality of research data and the ability to verify and authenticate the data and findings in a research study are very important in a qualitative research study. This requires more than just the demand for a research study to come up with reasonable conclusions and findings, but it also requires stronger commitments to data accuracy and transferable and verifiable research findings. Flick (2010) noted that the

Issue of quality in qualitative research is located on the level of research planning - from indication of research designs and methods to quality management - on the level of process evaluation, research training, and the relation of attitude and technology - or art and method - in research. (p. 401)

Therefore, in order to stay abreast of the research process, it is essential that the researcher ask similar question that Creswell (2012) put forth: "How do you evaluate the quality of your research?" Creswell (2012) stated that "Both during the process of conducting a study as well as at its conclusion, you need to be mindful of the quality of the research" (p. 282). He went on to add that "The improvement of practice, the quality of policy debates, and the advancement of knowledge all call for high-quality educational research" (p. 282 \& 283).

With all that said and done, IPA research study should evaluate its research design and planning to make sure that everything is pointing in the right direction - A quality research study. Phenomenological research study should make sure that quality is paramount in everything that the study does and produces. As a starter, the researcher should ascertain that the selection process of participants is done with the utmost 'carefulness' and integrity, so that the research participants and sites are selected for the right reasons and on the bases of the 'lived experiences' that the participants have purported to have experienced. More importantly, IPA research study should stay on top of any explicit and implicit biases that may jeopardize the goal and integrity of the study by bracketing (removing) the researcher's personal experience from the 'lived experiences' of the research participants. Additionally, IPA researchers should conduct a thorough research investigative procedure that will leave no stone unturned during the research study. Every important hint and lead, in the research, should be explored thoroughly. Ultimately, the aim of an IPA research study is to produce transferable and verifiable research findings with quality data collection procedures.

\section{Protection of human subjects}

The protection of human participants in a qualitative research study has always been a sacred obligation of the researcher, but more so for an IPA researcher. As an interpretative and 'participant-oriented' research approach, IPA research studies should endeavor to do everything within its power to protect the rights, dignities, and privacies of the research participants. The privacy of the research participants should never be compromised; it should always be paramount to the researchers. Therefore, every IPA research study should adhere to all the protection and privacy issues that may befall their research participants. Alase (2016) stated that

As a qualitative research study, it is imperative and ethically important that an IPA study is cognizant of the right and privacy of the individuals participating in the project. It is anticipated that participation in any IPA 
study will be strictly voluntarily based and the risks to the participants should be very minimal. It is, however, important that no harm should come to the participants in an IPA study. IPA research study should provide adequate measures of protection for the rights and dignities of its participants, because participants in an IPA study should be better off knowing they were able to tell the stories of their "lived experiences"; not worse off from it. (p. 92)

Protecting the right and privacy of the research participants is the most honorable thing that any research methodology (and traditions) can do to show, at a minimum, some kind of credibility and respect for their research studies. Therefore adhering to the "Protection of Human Subjects" requirements as stated and required by many higher institutions of learning in the U.S. is very important. Each of the participants invited to the research study should be advised of their rights; more importantly, a full disclosure of the intent and reason for the research study should be provided for the participants to see and read. In an IPA research, the participants should also be allowed, if any of them so chooses, to excuse themselves from the research study all together; or perhaps, refuse to answer any questions that they may not be comfortable with.

\section{IPA researcher's reflection statement}

\subsection{Researcher's self-reflection statement}

As a qualitative research approach that is 'participant-oriented' and an interpretive research tool, it is very important that researchers are in a state of constant 'self-reflections'; more so as a phenomenological researcher, one must have a sense of 'one-self' and the true understanding that one is truly intruding into another human beings' private space (life). Reflective statements are stated in almost every thesis paper; however, the problem is that very few thesis papers actually divulge the journey that the research process took for the researcher/researchers and the participants to get to the research finality. Halling (2008, p. 145) put it very concisely when she stated that "In everyday life each of us is something of a phenomenologist insofar as we genuinely listen to the stories that people tell us and insofar as we pay attention to and reflect on our own perceptions" (Cited in Smith et al., 2009). As such, Alase (2016) said that a "selfreflection' should be more than just a regular exercise that researchers casually give in a thesis paper, but more of a step-by-step detailed and descriptive journey of what it took for the researcher/researchers to get to their final destination (the research journey finality). In his post script reflection statement, Alase (2016) stated that

More importantly for an IPA researcher, it is vital that a post script reflection be added to the research as a way to cumulating [with] what the journey and the process were like before the research became was it is. It is important for researchers to tell the twists and turns of the process by giving a brief narrative of the researcher's journey. As a qualitative research study where subjectivity and interpersonal actions and experiences interplay with everyday life nuances, it is very important that a thick [and thoughtful] personal reflective description be included in the narrative of the research study, so that the audience can see for themselves the journey that the research study has gone through. As a matter of fact, interpretative phenomenological analysis (IPA) research study holds that it is important that every research study give a detail account of the mountains each study has climbed to get to their individual final destinations. For a research study to be authentic and credible, telling a narrative of the journey should be part of the research study's narration. The truth of the matter is that life is noting, but what we make of it as participants in this experiential life journey; it is up to each research study to tell their stories and allow the audience to partake in the journey with them. (p. 146-149)

\section{Components of IPA research}

The importance and essence of a phenomenological research approach (IPA) is its ability to explore, investigate, and interpret the 'lived experiences' of the research participants. Creswell (2013) asserted that qualitative research has the exploratory capacity to investigate, interpret, and understand the problematic issues in any qualitative research studies. He stated that "We conduct qualitative research because a problem or issue needs to be explored" and phenomenological approach is the most appropriate tradition to use in getting to the root-cause of the phenomenon (Creswell, 2013, p. 47). Therefore, in a phenomenological (IPA) research study, the essence of a purpose statement is that the research project has a phenomenon that it wants to explore (or investigate).

\section{Conclusion}

In conclusion, it is important for IPA researchers to know that the essence of this qualitative research approach is not to be a self-aggrandizing approach mechanism, but to be a research approach that helps understand, interpret, and amplify the 'lived experiences' of the research participants and make their experience a meaningful and dignified one. To that end, Alase (2016) stated that

The quality of any qualitative research finding is extremely important to the credibility of a study. More importantly, the analytical tool utilized by the research study to analyze the findings is also a very important tool in the analytical process. As a qualitative research approach, IPA approach analyzes the findings that the research study uncovered. Furthermore, IPA approach must create a standard that makes it unique and exceptional in analyzing research findings. As a standard of excellence in a phenomenological research study, Creswell (2013, p. 260) stated that the "standard that I would use to assess the quality of a phenomenology would be:

- Does the author convey an understanding of the philosophical tenets of phenomenology?

- Does the author have a clear "phenomenon" to study that is articulated in a concise way? 
- Does the author use procedures of data analysis in phenomenology, such as the procedures recommended by Moustakas (1994) or van Manen (1990)?

- Does the author convey the overall essence of the experience of the participants? Does this essence include a description of the experience and the context in which it occurred?

- $\quad$ Is the author reflective throughout the study? (p. 152-153)

The above 'standard questions' must be applied uniformly to every IPA research studies conducted across the board. As a matter of fact, IPA researchers should ask themselves the above questions because their answers will guide them in their quest to produce credible and transferable research studies (and results).

\section{References}

Alase, A. O. (2016). The impact of the Sarbanes-Oxley Act (SOX) on small-sized publicly traded companies and their communities (Unpublished doctoral dissertation), Northeastern University.

Asmussen, K. J., \& Creswell, J. W. (1995). Campus response to a student gunman. Journal of Higher Education, 66(5), 575-591

Burrell, G., \& Morgan, G. (1979). Sociological paradigms and organizational analysis. Farnham, UK: Ashgate Publishing.

Creswell, J. W. (2003). Research design: Qualitative, quantitative and mixed methods approaches. Thousand Oaks, CA: Sage Publications.

Creswell, J. W. (2012). Educational Research: Planning, Conducting and Evaluating Quantitative and Qualitative Research (4th Ed.). Boston, MA: Pearson.

Creswell, J. W. (2013). Qualitative Inquiry and research design choosing among five approaches (3rd Ed). Thousand Oaks, CA: Sage Publications.

Flick, U. (2010). An introduction to qualitative research (4th Ed.). New Delhi, India: Sage Publication.

Geertz, C. (1973). The interpretation of cultures. New York, NY: Basic Books, Inc.

Giorgi, A. (1994). A phenomenological perspective on certain qualitative research methods. Journal of Phenomenological Psychology, 25(2), 190-220.

Graneheim, U. H., \& Lundman, B. (2004). Qualitative content analysis in nursing research: concepts, procedures and measures to achieve trustworthiness. Nursing Education Today, 24(2), 105-112.

Guba, E. G. (Ed.). (1990). The paradigm dialog. Sage Publications.

Halling S. (2008). Intimacy, Transcendence, and Psychology. New York, Palgrave.

Husserl, E. (1931). Ideas: General introduction to pure phenomenology (D. Carr, Trans.). Evanston, IL: Northwestern University Press.

Mertler, C. A. (2006). Action research: Teachers as researchers in the classroom. Thousand Oaks, CA: Sage.

Miles, M. B., Huberman, A. M., \& Saldana, J. (2013). Qualitative data analysis: A methods sourcebook (3rd Ed.). Thousand Oaks, CA: Sage Publications.

Moustakas, C. (1994). Phenomenological research methods. Thousand Oaks: Sage.

Nicholas, D. B., Lach, L., King, G., Scott, M., Boydell, K., Swaatzky, B., Reisman, J., Schippel, E., \& Young, N. J. (2010). Contrasting internet and face - to - face focus group for children with chronic health conditions: Outcomes and participant experiences. International Journal of Qualitative Methods, 9(1). 105-121.

Polkinghorne, D. E. (1989). Phenomenological research methods. In R. S. Valle \& S. Halling (Eds.). Existential phenomenological perspectives in psychology (pp. 41-60). New York Plenum.

Riemen, D. J. (1986). The essential structure of a caring interaction: Doing phenomenology. Nursing research: $A$ qualitative perspective, 85-105.

Rubin, H. J. \& Rubin, I. S. (2012). Qualitative interviewing the art of hearing data (3rd Ed.). Thousand Oaks, CA: Sage.

Scriven, M. (1991). Prose and cons about goal-free evaluation. Evaluation Practice, 12(1), 55-63.

Smith, J. A. (1996). Beyond the divide between cognition and discourse: Using interpretative phenomenological analysis in health psychology. Psychology and health, 11(2), 261-271.

Smith, J. A., Flowers, P., \& Larkin, M. (2009). Interpretative phenomenological analysis: Theory, method and research. Los Angeles, CA: SAGE

Thomas, D. R. (2006). A general inductive approach for analyzing qualitative evaluation data. American Journal of Evaluation, 27(2), 237-246.

Trede, F., \& Higgs, J. (2009). Framing research questions and writing philosophically: The role of framing research questions. In J. Higgs, D. Horsfall, \& S. Grace (Ed.). Writing qualitative research question on practice (pp. 13-25). Rotterdam: Sense.

van Manen, M. (1990). Researching lived experience: Human science for an action sensitive pedagogy. Albany State University of New York Press.

Wolcott, H. F. (1983). Adequate schools and inadequate education: The life history of a sneaky kid. Anthropology and Education Quarterly, 14(1), 2-32.

$\mathrm{Wu}, \mathrm{L} . \& \mathrm{Wu}, \mathrm{M}$. (2011). The Employee dissatisfaction with organizational change: An Empirical study of a technology service company. African Journal of Business Management, 5(4), 1304. 